\title{
A LITERATURA AFRO-AMERICAN
}

\section{THE AFRO-AMERICAN LITERATURE}

\section{LA LITERATURA AFRO-AMERICAN}

\section{Lucília Teodora Villela de Leitgeb Lourenço ${ }^{1}$}

1. Mestre pela UFRGS e Pos Doutoranda na UFMS campus de Campo Grande/MS, Professora nível 5 da Universidade Estadual de Mato Grosso do Sul. Atua no curso de Letras Inglês com Literaturas Britânica. Norte-americana, de Língua Inglesa com foco no Pós Colonial. Dourados/MS, Brasil. Contato: luciliadeleitgeb@terra.com.br

RESUMO: Esta análise denominada "Estudo da tradução brasileira do livro "O Olho Mais Azul” acessa Estudos Culturais, Literários e Estudos da Tradução com o objetivo de analisar a tradução além da perspectiva logocêntrica, focando em manifestações culturais expressos pela língua. Neste estudo de caso atenção será focada nas vozes do livro pela escritora norte-americana e afrodescendente Toni Morrison, e como ela desafia os pressupostos brancos, patriarcais, protestantes e critérios Protestantes em que está baseado o contexto cultural dos Estados Unidos. Nossa investigação toma como ponto de partida o plano linguístico em que Morrison opta por usar não somente a norma culta da Língua Inglesa, mas a variante Black English, um registro que abre espaço para a diferença. Neste estudo, a tradução brasileira de The Bluest Eye em Português O Olho Mais Azul por Manuel Paulo Ferreira é o alvo de análise a partir da perspectiva culturalista.

Palavras-chave: Literatura AfroAmericana. Dialeto Negro. Racismo. Segregação.

\begin{abstract}
This analysis called "Study of the Brazilian translation of the book "O Olho Mais Azul" accesses Cultural, Literary and Translation Studies in order to analyze the translation beyond the logocentric perspective, focusing on cultural manifestations expressed by the language. In this case study, attention will be focused on the voices of the book by American writer and Afrodescendant Toni Morrison, and how she challenges the white, patriarchal, Protestant assumptions and Protestant criteria on which the cultural context of the United States is based. Our investigation takes as a starting point the linguistic plan in which Morrison chooses to use not only the cultured norm of the English language, but the Black English variant, a record that makes room for difference. In this study, the Brazilian translation of The Bluest Eye in Portuguese O Olho Mais Azul by Manuel Paulo Ferreira is the target of analysis from a culturalist perspective.
\end{abstract}

Keywords: Afro-American Literature. Black dialect. Racism. Segregation.
RESUMEN: Este análisis denominado "Estudio de la traducción brasileña del libro "O Olho Mais Azul" accede a Estudios Culturales, Literarios y de Traducción para analizar la traducción más allá de la perspectiva logocéntrica, enfocándose en las manifestaciones culturales expresadas por la lengua. En este caso de estudio, la atención se centrará en las voces del libro de la escritora estadounidense y afrodescendiente Toni Morrison, y cómo desafía los supuestos blancos, patriarcales, protestantes y los criterios protestantes en los que se basa el contexto cultural de los Estados Unidos. Nuestra investigación toma como punto de partida el plan lingüístico en el que Morrison opta por utilizar no solo la norma culta del idioma inglés, sino la variante del Black English, un registro que deja espacio para la diferencia. En este estudio, la traducción brasileña de El ojo azul al portugués $O$ Olho Mais Azul de Manuel Paulo Ferreira es objeto de análisis desde una perspectiva culturalista.

Palabras-clave: Literatura Afroamericana. Dialecto Negro. Racismo. Segregación.

Recebido em: 08/09/2020

Aprovado em: 10/11/2020

Todo o conteúdo deste periódico está licenciado com uma licença Creative Commons (CC BY-NC-ND 4.0 Internacional), exceto onde está indicado o contrário. 


\section{Introdução}

Toni Morrison despontou como escritora em plena ebulição dos direitos civis nos Estados Unidos e sua produção literária utiliza-se da literatura como ferramenta de resistência, lembrando ao mundo os horrores da escravidão. Suas páginas são permeadas pelo Black English Vernacular que penetra em nosso sangue por meio de uma língua melodiosa. Seu primeiro livro publicado em 1970, foi produto do preparo de suas aulas como Professora de Língua inglesa em 1965 e escrito em forma de conto, tendo posteriormente evoluído para o romance The Bluest Eye, que, embora alcançasse sucesso da crítica, não foi aceito pelo público norte-americano.

Nos Estados Unidos, literatura Afra-American, de viés cultural se especializou na temática da diáspora africana, clamando pelo seu espaço na literatura, lembrando as mazelas da escravidão. A escrita negra invariavelmente utiliza o dialeto em diálogos de personagens. Nos textos das escritoras deste grupo está presente o meio de comunicação intra-étnico, o African American Vernacular English, Ebonics, Black English ou Spoken Soul. Como se pode verificar em (RICKFORD, 2000:3) a denominação de Spoken Soul foi criada por Claude Brown in 1968.

\section{O uso do Ebonics e a dificuldade de aprender a norma padrão}

O primeiro pesquisador do Ebonics foi William Labov cujo modelo linguístico estabelecido permitiu compreender que as estruturas variantes, muito mais que as invariantes, revelam padrões de regularidade presentes na língua que não são produzidos pelo mero acaso. Numa língua que serve à uma comunidade complexa e real, a ausência de heterogeneidade estruturada é que seria disfuncional ( WEINREICH, 1968, p. 647-84).

O termo Ebonics foi cunhado em 1972 pelo psicólogo Robert L. Williams autor do teste Black Intelligence Test of Cultural Homogeneity elaborado para dar aos afrodescendentes uma oportunidade nos testes de inteligência comuns, desenhado para o vocabulário do branco, fato que provocou a conclusão errônea que os negros são inferiores intelectualmente.

Com relação aos testes de inteligência aplicados nas escolas Homi Bhabha em O Bazar Global e o Club dos Cavalheiros Ingleses tem reflexões para com a questão dialetal dentro do rígido sistema da sociedade e sistema educacional norte-americano. Sabe-se que as crianças negras recebem a língua através do dialeto falado em seus lares e com a comunidade negra e as dificuldades surgem na época da inclusão escolar quando as dificuldades linguísticas das crianças negras se avolumam. O uso do Ebonics e o desconhecimento do inglês padrão faz com que muitas crianças sejam colocadas injustamente em classes de educação especial, fato que as leva à alfabetização precária e à perpetuação ao subemprego. Homi Bhabha pontua suas reflexões e manifesta sua sugestão: 
As descrições e as definições sociolingüísticas de vernaculização certamente têm importante contribuição pedagógica a dar. Quem poderá negar que um conhecimento da estrutura profunda do inglês dos negros não iria auxiliar os professores em suas tentativas de avaliar o desempenho e de extrair os melhores resultados daqueles que estão em desvantagem do ponto de vista educacional? (BHABHA, 2011, p. 64-65).

Na literatura o dialeto / idioleto surge dialogicamente, matizando o texto. Tendo em vista a relevante relação entre tradução e cultura, objetiva-se com este estudo examinar como as questões de linguagem de âmbito cultural representadas nas traduções pelo dialeto African American Vernacular English no texto morrisoniano The Bluest Eye foram resolvidas pelo tradutor de "O Olho Mais Azul”, Manuel Paulo Ferreira.

\section{.Características do Black English Vernacular}

Apresento a seguir uma pequena amostragem das construções gramaticais e de sintaxe da desconhecida variedade linguística Ebonics, atualmente considerada língua, com a finalidade de facilitar a identificação do dialeto. Vejam-se breves exemplos de suas características:

- Omissão da cópula be, em formas contraídas 's e 're: He quick in everything. You out of game.

- Inclusão do be para aspecto habitual ou tempo futuro: they be slow all the time. The boy be here soon.

- Repetição do pronome substantivo sempre que a referência for terceira pessoa: Miss Nelle she pointed... Shelby he told us...

- Aspecto inclusivo do done: You done gone and bought your father a hat?

- Múltipla negação: there aint nothing the matter.

- Supressão da primeira sílaba não marcada: because /Kauz/expect/spek/about/bawt/

- Uso do ain’t: como forma negativa de is-are-am e excluindo os auxiliares have e has.

- Simplificação da consoante: Na oralidade destacamos: grand/graem/moved /muv/just/jis

- Simplificação de ditongos: My/mah/time/tahm/I/ah /rice/rahce

- Padrões interrogativos sem do: What he want?

A seguir, apresentamos uma amostragem de fragmentos do romance Beloved (1987), com o uso do Black English ${ }^{1}$ e tradução nossa.

\footnotetext{
${ }^{1}$ Todos oXXs fragmentos foram extraídos da edição norte-americana de 1987.
} 
Can't nobody catch up on eighteen years in a day (MORRISON, 1987, p. 11). ${ }^{2}$

Ninguém pode lembrá dezoito anos num dia

/ Nobody can catch up on eighteen years in a day /

Men don't know nothing much (p. 16).

Os home num sabe de nada

/Men don't know anything much /

We was talking' bout a tree, Sethe (p. 16).

Nóis tava falano di uma arvre, Sethe.

/We were both talking about a tree, Sethe /

Them boys found out I told on em (p. 17).

Os meninu descobriro que eu denunciei eles

/ The boys found out I told them I

I never touched no velvet (p. 33).

Nunca peguei in veludo ninhum

/ have never touched any velvet /

I still think it was them questions that tore Sixo up (p. 37).

Inda achu qui foi a pergunta deles qui destruiu Sixo.

/I still think it was their question that tore Sixo up /

Litle rice, litle bean, No meat in between. Hard work ain't easy, Dry bread ain't greasy (p. 40).

Poco arroz, poco feijão. Sem carne nu meio. Trabalho pesado nun é brinquedo; pão seco nun tem banha.

/ Little rice, little bean. No meat in between. Hard work isn't easy, Dry bread isn't greasy/ I was thinking of looking for work arond here. What you think? (p. 41).

Tava pensano in procurá um trabaio perto daqui. O que acha?

/I was thinking of looking for work around here. What do you think? I

Ain't much. River mostly. And hogs (p. 41).

Num tem muito por aqui. Rio, na maior parte. E porcos.

/ There isn't much. River mostly. And hogs /

But it wasn't going to be nothing (p. 59).

Mais num ía tê nada.

/ But it wasn't going to be anything /

She never fixed my hair nor nothing (p. 60).

Ela nunca ajeitô meu cabelo nem nada.

/ She has never fixed neither my hair nor anything /

Paul D be here in a minute, she said (p. 62).

Paul $\mathrm{D}$ vai tá aqui in um minuto, ela disse.

/Paul D will be here in a minute, she said /

\section{Análise da tradução de trechos de The Bluest Eye}

Em sua narrativa, Toni Morrison apropria-se literariamente do conceito de cultura no qual a língua é condição intrínseca para sua organização e sua fixação. A oralidade do dialeto surge aos poucos durante o decorrer da narrativa qual um matiz para, no final, explodir no fluxo de consciência proferido pela mãe da pequena protagonista Pécola, apresentado abaixo.

\footnotetext{
${ }^{2}$ Optamos apenas pela tradução do dialeto, sem considerar a rima.
} 


\section{Exemplo 1}

"The onliest time I be happy seem like was when I was in the picture show. Every time I got, I went. I'd go early, before the show started. They'd cut off the lights, and everything be black. Then the screen would light up and I'd move right on in them pictures. I'member one time I went to see Clark Gable and Jean Harlow. I fixed my hair up like I'd seen hers on a magazine"

Parece que a única hora que eu era feliz era quando tava no cinema. Ia sempre que podia. Chegava cedo, antes do filme começar. A luz se apagava e ficava tudo escuro. Aí a tela se iluminava e eu entrava direto no filme. (MORRISON, 2003, p. 124)

Como se pode observar, o tradutor resolve a primeira marca do Ebonics usando a forma oral do verbo ser - tava. Para a segunda marca, o tradutor não apresenta nenhuma solução em língua portuguesa. Vejamos mais alguns exemplos: EXEMPLO 2

"I'member one time I went to see Clark Gable and Jean Harlow. I fixed my hair up like I'd seen hers on a magazine"

\section{Exemplo 2}

"I'member one time I went to see Clark Gable and Jean Harlow. I fixed my hair up like I'd seen hers on a magazine".

Lembro que uma vez fui ver o Clark Gable e a Jean Harlow. Penteio cabelo como o dela, como eu tinha visto numa revista." (MORRISON, 2003, p. 125).

Neste exemplo, pode-se perceber que a omissão da primeira sílaba do verbo - remember - member - não possibilita uma transferência para o português. A tradução, assim, apenas tira do verbo a partícula reflexiva - lembro-me.

\section{Exemplo 3}

"He begin to make madder than anything, I knowed, and I couldn't keep my hands off him."

Ele me deixava louca da vida e eu tava sempre caindo de tapa em cima dele. (MORRISON, 2003, p. 125).

Aqui, a autora transforma um verbo irregular em regular, o que é normal ocorrer no Ebonics. Como o português não teria possibilidade de mostrar esta marca, o tradutor transforma todo o período em linguagem falada. 


\section{Exemplo 4}

"But it weren't like I thought it was gone be I loved them and all, I guess, but maybe it was having no money, or maybe it was Cholly, but they sure worried the life out of me."

Mas não foi como eu achei que ia ser. Eu gostava deles e tudo, eu acho, mas por causa da falta de dinheiro ou por causa de Cholly eu me preocupava muito com eles. (MORRISON, 2003, p. 126). Neste caso, tem-se um sujeito no singular - it - e um verbo no plural - weren't - e a expressão gone be, outra característica do Ebonics de não usar a norma - going to be. O tradutor, por sua vez, não marca o uso do verbo em pessoa diferente nem o uso da expressão no particípio, mas procura trazer essas marcas através da oralidade no período.

No exemplo a seguir, pode-se perceber como as implicações de ordem cultural participam ativamente da escritura do texto em sua língua de origem, mas não se fazem presentes na tradução para outras línguas, como no caso deste trabalho, o português do Brasil.

Vejamos um trecho em inglês e sua tradução em português:

\section{Exemplo 5}

[...] 'Here. Here's a quarter. Gone over to Isaleys's and get yourself some ice cream. You been good girls, aint you?

His light green words restaured the color of the day. "Yes, thank you Mr. Henry. Will you tell Mama for us if she comes?"

"Sure. But she ain't due back for a spell".

“Tomem, vinte e cinco centavos. Vão até a Isaley’s e comprem sorvete. Vocês se comportaram, não se comportaram?"

As palavras verde-claras dele restauraram a cor do dia. "Sim, senhor. Obrigada, senhor Henry. O senhor conta à mamãe aonde nós fomos, se ela chegar?”

“Claro. Mas ela vai demorar.” (MORRISON, 2003, p. 78.)

\section{Considerações finais}

A tradução do trecho acima, como se pode ver, apaga totalmente a oralidade do dialeto.

Em que pese o fato de que a nota do tradutor apresentada no final do posfácio afirme "cito [...] fez-se todo o possível para manter o tom oral, sonoro e coloquial, sobretudo nos diálogos”(MORRISON, 2003, p. 216), expressamos nosso desacordo diante, por exemplo, da tradução acima apresentada, que não é a única na totalidade da obra.

Apesar das importantes contribuições à tradução apresentadas por Benjamin, Pound, Campos e Venuti, a criatividade na prática tradutória não é compartilhada por outros tradutores e é até desaconselhada. 
Merece menção a inclusão neste ensaio das reflexões de Clifford Landers, pelas suas ideias contrárias aos teóricos/tradutores que exploravam a criatividade em suas traduções expostos anteriormente. Landers é professor da New Jersey University e tradutor para o Português do Brasil para Inglês. Landers está habituado com diversos níveis de linguagens, regionalismos já que incluiu entre seus trabalhos Moacyr Scliar, Raquel de Queiroz, João Ubaldo Ribeiro, Rubem Fonseca, Chico Buarque, Lima Barreto, Osman Lins, Jô Soares, Jorge Amado, além de José de Alencar, conforme informações presentes na contracapa de seu livro. No entanto, no que se refere ao ato tradutório de variação linguística, rechaça por inteiro a tradução de dialetos, considerados como um dilema, um desafio ímpar na tradução literária.

Apresenta-se a seguir o solilóquio da personagem MRS Breed love pontuando em negrito o uso do dialeto African American Vernacular English ou Black English.

I ever did over that. Everything went then. Look like I just didn't care no more after that. I let my hair go back, plaited it up, and settled down to just being ugly. I still went to the pictures, though, but the meanness got worse. I wanted my tooth back. Cholly poked fun at me, and we started fighting again. I tried to kill him. He didn't hit me too hard, 'cause I were pregnant I guess, but the fights, once they got started up again, kept up. He begin to make madder than anything, I knowed, and I couldn't keep my hands off him. Well, I had that baby__a boy__ and after that I got pregnant again with another one. But it weren't like I thought it was gone be. I loved them and all, I guess, but maybe it was having no money, or maybe it was Cholly, but they sure worried the life out of me. Sometimes I'd catch myself hollering at them and beating them, and I'd feel sorry for them, but I couldn't seem to stop. When I had the second one, a girl, I'd member I said I'd love it no matter what it look like. She looked like a black ball of hair. I don't recollect trying to get pregnant. Maybe 'cause I'd had one already and wasn't scared to do it. Anyway, I felt good, and wasn't thinking on the carrying, just the baby itself. I used to talk to it whilst it be still in the womb. Like good friend we was. You know. I be hanging wash and I knowed lifting weren't good for it. I'd say to it hold on now I gone hang up these few rags, don't get froggy; it be over soon. I wouldn't leap or nothing. Or I be mixing something in a bowl for the other chile and I'd talk to it then too. You know, just friendly talk. On up til the end I felted good about the baby. I went to the hospital when my time come. So I could be easeful. I didn't want to have it at home like I done with the boy. They put me in a big room with a whole mess of women. The pains was coming, but not too bad. A little odd doctor come to examine me. He had all sorts of stuff. He gloved his hand and put some kind of jelly on it and rammed it up between my legs. When he left off, some more doctors come. The old one and some young ones. The old one was learning the young ones about babies. Showing them how to do. When he got to me he said now these here women you don't have any trouble with. They deliver right away and with no pain. Just like horses. The young ones smiled a little. The looked at my stomach and between my legs. They never said nothing to me. Only one looked at me. Looked at my face, I mean. I looked right back at him. He dropped his eyes and turned red. He knowed, I reckon, that maybe I weren't no horse foaling. But them others. They didn't know. They went on. I seed them talking to them white women: "How you feel? Gonna have twins?" Just shucking them, of course, but nice talk. Nice friendly talk. I got edgy, and when them pains got harder, I was glad. Glad to have something else to think about. I moaned something awful. The pain wasn't as bad as I let on, but I had to let them people know having a baby was more than a bowel movement. I hurt just like them white women. Just 'cause I wasn't hooping and hollering before didn't I wasn't feeling pain. What ' $d$ they think? That just 'cause I knowed how to have a baby with no fuss that my behind wasn't pulling and aching like theirs? Besides, that doctor don't know what he was talking about. He must seem no mare foal. Who say they don't have no pain? Just 'cause she don't cry? 'Cause she can't say it they think it ain't there? If they looks in her eyes and eye balls lolling back, see the sorrowful look, they'd know. Anyways, the baby come. Big old see them healthy thing. She looked different from what I thought. 
Reckon I talked to it so much before I conjured up a mind's eye view of it. So when I seed it was like looking at a picture of your mama when she was a girl. You knows who she is, but she don't look the same. They give her to me for a nursing, and she liked to pull my nipple off right away. She caught on fast. Not like Sammy, he was the hardest child to feed. Bet Pecola look like she knowed right off what to do. A right smart baby she was. I used to like to watch her. You know they makes them greedy sounds. Eyes all soft and wet. A cross between a puppy and a dying man. But I knowed she was ugly. Head full of pretty hair, but Lord, she was ugly." (MORRISON, 1994, p. 123-126).

Parece que a única hora que eu era feliz era quando tava no cinema. Ia sempre que podia. Chegava cedo, antes do filme começar. A luz se apagava e ficava tudo escuro. Aí a tela se iluminava e eu entrava direto no filme. O homem branco tomando conta tão bem da mulher, e todos bem-vestido, as casa grande e limpa, com a banheira no mesmo aposento que o toalete. Aqueles filme me dava muito prazer, mas depois ficava difícil votar para casa e olhar para o Cholly. Não sei. Lembro que uma vez fui ver o Clark Gable e a Jean Harlow. Penteei o cabelo como o dela, como eu tinha visto numa revista. Uma risca de lado, com um cachinho na testa. Ficou igualzinho o dela. Bom, quase igualzinho. Sentei naquele cinema, com o cabelo penteado daquele jeito e gostei muito. Resolvi ver o filme até o fim de novo e levantei para ir comprar um doce. Voltei pro meu lugar, dei uma grande mordida no doce e ele me arrancou um dente. Tive vontade de gritar. Os meus dente era bom, eu não tinha nenhum dente estragado na boca. Não dava pra acreditar. Eu, grávida de cinco mês, tentando ficar parecida com a Jean Harlow, e sem dente da frente. Depois disso foi tudo por água abaixo. Parece que eu não liguei para mais nada. Parei de me preocupar com o cabelo, fazia uma trança e pronto, e resolvi ser feia. Ainda ia no cinema, mas tudo ficou pior. Eu queria o meu dente de volta. O Cholly caçoava de mim e a gente começou a brigar de novo. Eu tentei matar ele. Ele não me batia com muita força, acho que porque eu estava grávida, mas as briga, depois que começou de novo, continuou. Ele me deixava louca da vida e eu tava sempre caindo de tapa em cima dele. Bom, eu tive aquele bebê_um menino_e depois fiquei grávida de novo. Mas não foi como eu achei que ia ser. Eu gostava deles e tudo, eu acho, mas por causa da falta de dinheiro ou por causa de Cholly eu me preocupava muito com eles. ‘̀̀s vezes eu berrava com eles e batia neles, e sentia pena, mas não conseguia parar. Quando tive o segundo, uma menina, lembro que eu disse que ia gostar do bebê, mesmo que não fosse bonito. Ela parecia uma bola preta de cabelo. Não lembro de tentar engravidar da primeira vez. Mas na segunda eu tentei. Talvez porque já tinha um não tinha mais medo. O que eu sei é que me sentia bem e não pensava em gravidez, só no bebê. Conversava com ele enquanto ainda tava na barriga. A gente era bons amigos. Você sabe. Eu ia pendurar a roupa lavada e sabia que levantar peso não era bom pra ele. Então eu dizia pra ele aguentar firme, porque eu ia pendurar alguns pano e ele não precisava começar a pular, porque ia se rápido. Ele não pulava nem nada. Ou então eu tava misturando alguma coisa numa tigela pra outra criança e também conversava com ele. Conversa assim de amigo. Até o final eu me senti bem com aquele bebê. Quando chegou a hora, fui para o hospital. Pra não ter preocupação. Não queria que nascesse em casa, como o menino. Me puseram num quarto grande, com um bando de mulher. A dor tava vindo, mas não muito forte. Um médico baixinho e velho veio me examinar. Ele tinha um montão de instrumento. Pôs uma luva, passou um creme na mão e enfiou a mão entre minhas pernas. Depois que ele foi embora, vieram outros médico. Um velho e outros moço. $O$ velho tava ensinando os moço sobre bebês. Mostrando como fazer, quando chegou a minha vez, ele disse que com essas mulheres vocês não têm problema algum. Elas dão à luz logo e sem dor. Exatamente como as égua. Os moço deu um sorrisinho... Olharam a minha barriga e entre as minha perna. Não me disseram um palavra. Só um olhou para mim, pro meu rosto. Eu encarei ele, ele baixou a vista e ficou vermelho. Acho que ele entendeu que eu talvez não era uma égua parindo. Mas os outro não entendeu. Foram em frente. Eu vi eles conversando com as mulher branca : Como está se sentido? Vai ter gêmeos?' Conversa à toa, é claro, mas conversa boa e atenciosa. Eu fiquei nervosa e, quando as dor piorou, fiquei contente. Contente de ter outra coisa pra pensar. Gemi muito. As dor não tava assim tão forte, mas eu tinha que fazer aquela gente saber que ter um bebê era mais do que ter vontade de ir ao banheiro. Eu sentia tanta dor quanto as branca. Não era porque eu não tava gritando e berrando antes que eu não tava sentindo dor. O que é que eles pensava? Que só porque eu sabia como ter um bebê sem fazer espalhafato meu travesseiro não tava repuxando e doendo como o delas? E também 
aquele médico não sabia o que tava falando. Ele nunca deve ter visto uma égua parir. Quem disse que ela não sente dor? Só porque não grita/ só porque ela não sabe gritar, eles pensa que a dor não tá lá? Se eles olhasse no olho dela e visse os globo arregalado, visse o olhar aflito, eles ia saber. Bom, o bebê veio. Grande e saudável. Ela era diferente do que eu tinha imaginado. Acho que conversei tanto com elefantes que criei uma imagem na cabeça. Então, quando vi, foi como olhar uma fotografia da mãe da gente quando ela era menina. A gente sabe quem é, mas não parece a mesma pessoa. Me deram o bebê pra amamentar e na mesma hora ela gostou de puxar o bico do meu peito. Aprendeu rápido. Não como o Sammy, que foi uma criança mais enjoada pra alimentar. Mas a Pecola, desde o começo parecia que ela sabia o que tinha que fazer. Um bebê esperto. Eu gostava de olhar pra ela. Ela faz uns barulhinho guloso. O olho meigo e úmido. Cruzamento de cachorrinho e homem morrendo. Mas eu sabia que ela era feia. A cabeça coberta de um cabelo bonito, mas, meu Deus, como ela era feia. (MORRISON, 2003, p. 124-127)

\section{Referências}

AFRICAN AMERICAN VERNACULAR ENGLISH. Dialect. Available in: <http://en.wikipedia.org/wiki/African_American_Vernacular_English>. Acesso em: 30 ago. 2012.

BHABHA, Homi K. O local da cultura. Translation by Myriam Ávila, Eliana Lourenço de Lima Reis and Gláucia Renata Gonçalves. 2. ed. Belo Horizonte: UFMG, 2003. (Humanitas).

BARTHES, Roland. A morte do autor. In: Laranjeira. São Paulo: Brasiliense, 1988. p. 53. . (Org.). O rumor da língua. Translation by Mario

BASSNETT, Susan. Comparative literature: A critical introduction. Oxford: BlackWell, 1993.

CAMPOS, Haroldo de. Da tradução como crítica e criação. In: . Metalinguagem \& outras metas.

São Paulo: Perspectiva, 1992. p. 31-42.

DILLARD, Joey Lee. Black English: Its history and usage in the United States. New York: Random House, 1972.

DORIAN, Nancy C. Varieties of variation in a very small place: Social homogeneity, prestigie norms, and linguistic variation. Language - Journal of the Linguistic Society of America, Baltimore, v. 70, n. 4, p. 631696, 1994.

HATTNHER, A. L. Presença de autores afro-americanos no Brasil: As traduções. Crop Revista da Área de Língua e Literatura Inglesa e Norte Americana, São Paulo, v. 4/5, p. 297-313, 1998.

ISER, Wolfgang. A interação do texto com o leitor. In: LIMA, Luiz Costa. (Org.). A literatura e o leitor: textos de estética da recepção. Translation by Luiz Costa Lima. Rio de Janeiro: Paz e Terra, 1979. p. 83132.

JAUSS, Hans Robert. A estética da recepção: colocações gerais. In: LIMA, Luiz Costa. (Org.). A literatura e o leitor: textos de estética da recepção. Translation by Luiz Costa Lima. Rio de Janeiro: Paz e Terra, 1979. p. 43-61.

LABOV, William. Language in Inner City: Studies in the black english vernacular. Philadelphia: University of Pennsylvania, 1984.

Sociolinguistic patterns. Philaldelphia: University of Pennsylvania Press, 1972.

. Tradução e teoria de polissistemas. Miscelania, v. 3, p. 175-178, 1998.

MORRISON, Toni. The bluest eye. New York: Plume, 1994.

. O olho mais azul. Translation by Manoel Paulo Ferreira. São Paulo: Companhia das Letras, 2003. 